\title{
Changes in Tolerance to Partial Desiccation and in Metabolite Content of Celery Somatic Embryos Induced by Reduced Osmotic Potential
}

\author{
Yehoshua Saranga, Y.-H. Kim, and Jules Janick \\ Department of Horticulture, Purdue University, West Lafayette, IN 47907 \\ Additional index words. Apium graveolens, synthetic seed, abscisic acid, amino acids, carbohydrates, fatty acids
}

\begin{abstract}
Effects of reduced osmotic potential on somatic embryos of celery (Apium graveolens L.) were studied in an attempt to understand and improve their tolerance to partial desiccation. Embryos responded similarly to application of high osmoticum $\left(384 \mathrm{mOs} / \mathrm{kg} \mathrm{H}_{2} \mathrm{O} \mathrm{vs} .190 \mathrm{mOs} / \mathrm{kg} \mathrm{H}_{2} \mathrm{O}\right.$ in the control), achieved either by manipulation of sucrose or polyethylene glycol concentrations (PEG). Treatments of high osmotic concentration applied during the last 2 days of the embryo production cycle increased embryo survival and conversion after partial desiccation. The most striking effect of the high osmotic concentrations was the 4-fold increase in proline, while a 2-fold increase was obtained with 1 M ABA alone. Application of high osmotica decreased reducing sugars, increased sucrose, but did not affect starch content of embryos; of these responses, only the change in sucrose was similar to that induced by ABA. Osmotic treatments did not affect total fatty acid content in the embryos compared to the 2-fold increase induced by ABA. Chemical name used: abscisic acid (ABA).
\end{abstract}

During the last stage of seed development, embryos undergo a maturation process that includes a buildup of nutrient reserves, an arrest of tissue growth, the development of desiccation tolerance, and, in many seeds, the induction of dormancy. ABA levels in developing seeds are temporally correlated with the onset of maturation and the prevention of precocious germination (Quatrano, 1987). Similarly, ABA supplementation of somatic embryo culture medium has been shown to prevent germination (Ammirato, 1983), increase desiccation tolerance (Kitto and Janick, 1985), and induce maturation events (Rim and Janick, 1990, 1991).

Imposition of desiccation tolerance on somatic embryos is critical for the production of "dried synthetic seeds" (Janick et al., 1989). Under drastic desiccation, survival of celery somatic embryos is very low but improves with ABA application (Rim and Janick, 1989). Ameliorating the desiccation protocol to achieve gradual drying, based on encapsulation or increased relative humidity, also improves survivability (Kim and Janick, 1989). In addition, reduced osmotic potential during embryo production, mimicking the changes in normal zygotic seed environment, encourages maturation of somatic embryos (Buchheim et al., 1989) and induces development changes similar to those of zygotic or apomictic seeds (Finkelstein and Crouch, 1986).

A different approach to achieving desiccation tolerance is to supply desiccation protectants to the developing somatic embryos. Desiccation tolerance was increased by medium supplementation with proline alone but especially in conjunction with ABA (Kim and Janick, 1990, 1991; Saranga et al., 1992). Trehalose, a nonreducing disaccharide reported to stabilize membranes during desiccation in anhydrobiotic organisms (Crowe et al., 1984), may act both as an osmoticurn and as a desiccation protectant.

In this study we investigated the effects of reduced osmotic

Received for publication 12 Aug. 1991. Accepted for publication 28 Oct. 1991. Journal paper no. 12,637 of the Purdue Univ. Agricultural Experiment Station. We thank A. Altman, Faculty of Agriculture, Hebrew Univ. of Jerusalem, for providing the plant material. We gratefully acknowledge assistance of David Rhodes and A. Whipkey. The cost of publishing this paper was defrayed in part by the payment of page charges. Under postal regulations, this paper therefore must be hereby marked advertisement solely to indicate this fact. potential induced by sucrose, PEG, or trehalose on tolerance to partial desiccation of celery cultured with or without ABA. Changes in metabolite content induced by sucrose and PEG were compared with those induced by ABA.

\section{Materials and Methods}

Somatic embryo production, partial desiccation, and rehydration. Somatic embryos of 'SB 12' celery were produced, partially desiccated, and rehydrated using a procedure detailed in Saranga et al. (1992). Callus was induced from leaf explants in petri dishes containing callus induction medium consisting of MS basal medium (Murashige and Skoog, 1962) (salts plus vitamins) supplemented with $2.3 \mu \mathrm{M}$ (2,4-dichlorophenoxy)acetic acid (2,4-D), $2.3 \mu \mathrm{M}$ kinetin, casein hydrolysate at $0.5 \mathrm{~g} \cdot$ liter $^{-1}$, Gelrite (Scott Laboratories, Fiskeville, R.I.) at 3 $\mathrm{g} \cdot$ liter $^{-1}$, and sucrose at $30 \mathrm{~g} \cdot \operatorname{liter}^{-1}$ and adjusted to $\mathrm{pH} 5.8$ before autoclaving. After 28 days, callus was transferred into liquid embryo production medium (EPM) consisting of MS basal medium supplemented with $30 \mathrm{~g}$ sucrose/liter. Torpedo-shaped embryos were harvested after 10 days of the embryo-production cycle and used for desiccation tests or metabolite determination. Partial desiccation (to $\approx 60 \%$ water content) was carried out by exposing embryos to a $92 \%$ relative humidity (RH) for $48 \mathrm{~h}$. Embryos were rehydrated and kept on filter paper bridges for 10 days. Embryo survival (visible growth) and conversion (both root and shoot development) were expressed as a percentage of the total embryos desiccated; vigor of converted seedlings was estimated by fresh weight.

Embryos were treated with various osmotic agents applied by replacing $10 \mathrm{ml}$ of the standard EPM with $10 \mathrm{ml}$ of new EPM containing an appropriate amount of agent. At the same time, $10 \mathrm{ml}$ of medium was replaced with fresh EPM in the controls, to account for possible effects of fresh medium. ABA, when applied, was added to EPM on day 3 and kept 7 days until harvest.

Experimental procedures. A preliminary series of experiments was conducted to determine the optimal application of reduced osmotic potential, induced by increasing sucrose con-

Abbreviations: EPM, embryo production medium; GABA, $\gamma$-aminobutyrate; PEG, polyethylene glycol. 
Table 1. Desiccation tolerance of celery somatic embryos under normal culture conditions or reduced osmotic potential (for the last 2 days of the 10 culturing days), with or without $1 \mu \mathrm{M} \mathrm{ABA}$ (applied on day 3); 48-h desiccation, 92\% RH.

\begin{tabular}{|c|c|c|c|c|c|c|}
\hline \multirow{2}{*}{\multicolumn{2}{|c|}{ Treatment }} & \multirow{3}{*}{$\frac{\text { Expt. } 1^{z}}{\text { Survival }}$} & \multicolumn{3}{|c|}{ Expt. 2} & \multirow{3}{*}{$\begin{array}{c}\text { Mean } \\
\text { survival } \\
(\%)\end{array}$} \\
\hline & & & \multirow[b]{2}{*}{$\begin{array}{c}\text { Survival } \\
(\%)\end{array}$} & \multirow[b]{2}{*}{$\begin{array}{c}\text { Conversion } \\
(\%)\end{array}$} & \multirow{2}{*}{$\begin{array}{l}\text { Seedling } \\
\text { fresh wt } \\
\text { (g) }\end{array}$} & \\
\hline Osmotica ${ }^{y}$ & $\begin{array}{l}\text { ABA } \\
(\mu \mathrm{M})\end{array}$ & & & & & \\
\hline \multirow[t]{2}{*}{ Control } & 0 & 0.6 & 30.0 & 7.8 & 8.1 & 15.3 \\
\hline & 1 & 31.5 & 93.3 & 60.0 & 9.4 & 62.2 \\
\hline \multirow[t]{2}{*}{ Sucrose } & 0 & 5.6 & 60.0 & 16.7 & 12.7 & 32.8 \\
\hline & 1 & 51.6 & 95.5 & 83.6 & 12.8 & 73.3 \\
\hline \multirow[t]{2}{*}{ PEG } & 0 & 13.2 & 66.7 & 34.4 & 8.9 & 39.9 \\
\hline & 1 & 52.1 & 84.4 & 54.2 & 7.8 & 68.3 \\
\hline \multirow[t]{3}{*}{ Trehalose } & 0 & 4.4 & & & & \\
\hline & 1 & 39.4 & & & & \\
\hline & \multicolumn{6}{|c|}{ Main effects (probability of $F$ ) } \\
\hline \multicolumn{2}{|l|}{ Osmoticum } & 0.37 & 0.096 & 0.056 & 0.11 & \\
\hline \multicolumn{2}{|l|}{$\mathrm{ABA}$} & 0.001 & 0.004 & 0.003 & 0.81 & \\
\hline \multicolumn{2}{|l|}{ Interaction } & 0.89 & 0.017 & 0.10 & 0.81 & \\
\hline
\end{tabular}

${ }^{7}$ Conversion and plantlet fresh weight were not recorded.

${ }^{\mathrm{y}}$ Details of osmotic treatment in Materials and Methods.

centration for maximum embryo survival and conversion. Sucrose concentration of EPM was increased up to $12 \%(\mathrm{w} / \mathrm{v})$ for various periods, up to 5 days. These experiments indicated that application of $7 \%$ sucrose for the last 2 days of the embryo production cycle was optimal for increasing tolerance to partial desiccation.

To differentiate an osmotic effect from the sucrose effect, the following treatments of identical osmolarity were applied for the last 2 days of the 10-day embryo production cycle with or without $1 \mu \mathrm{M}$ ABA:

\begin{tabular}{|c|c|c|}
\hline $\begin{array}{l}\text { Treatment } \\
\text { name }\end{array}$ & Osmoticum & $\begin{array}{c}\text { Osmolarity } \\
\left(\mathrm{mOs} / \mathrm{kg} \mathrm{H}_{2} \mathrm{O}\right)\end{array}$ \\
\hline Control & $3 \%$ Sucrose & 190 \\
\hline Sucrose & $7 \%$ Sucrose & 384 \\
\hline PEG & $\begin{array}{l}3 \% \text { Sucrose }+10 \% \text { PEG } \\
\quad(\text { Mol wt } 8000)\end{array}$ & 382 \\
\hline Trehalose & $3 \%$ Sucrose $+4 \%$ trehalose & 386 \\
\hline
\end{tabular}

Two similar experiments were conducted (trehalose applied only in Expt. 1) with four replications (30 embryos each).

Table 2. Carbohydrate content of celery somatic embryos under normal culture conditions or reduced osmotic potential (for the last 2 days of the 10 culturing days) with or without ABA (applied on day

\begin{tabular}{|c|c|c|c|c|c|}
\hline \multicolumn{2}{|c|}{ Treatment } & \multicolumn{4}{|c|}{ Carbohydrates (mg $\cdot \mathrm{g}^{-1}$ dry wt) } \\
\hline Osmotica & $\begin{array}{l}\mathrm{ABA} \\
(\mu \mathrm{M})\end{array}$ & $\begin{array}{c}\text { Reducing } \\
\text { sugars }\end{array}$ & Sucrose & Starch & Total \\
\hline & \multicolumn{5}{|c|}{ Main effect of osmoticum } \\
\hline Control & & $50.6 \mathrm{a}^{\mathrm{z}}$ & $30.9 \mathrm{~b}$ & 131 & $212 \mathrm{c}$ \\
\hline Sucrose & & $42.4 \mathrm{~b}$ & $66.7 \mathrm{a}$ & 133 & 242 \\
\hline \multirow[t]{6}{*}{ PEG } & & $31.4 \mathrm{c}$ & $60.4 \mathrm{a}$ & 138 & $230 \mathrm{~b}$ \\
\hline & & $* * *$ & $* * *$ & NS & $* * *$ \\
\hline & \multicolumn{5}{|c|}{ Main effect of $A B A$} \\
\hline & 0 & 41.5 & 44.4 & 128 & 214 \\
\hline & 1 & 41.3 & 60.9 & 141 & 243 \\
\hline & & NS & $* * *$ & $* *$ & $* * *$ \\
\hline
\end{tabular}

$\overline{\mathrm{z}}$ Lowercase letters indicate significant differences at $P=0.05$ according to Student-Newman-Keuls' multiple range test.

$\mathrm{NS}^{\boldsymbol{Q}^{*}, * * * *}$ Nonsignificant or significant at $P=0.01$ and 0.001 , respectively.
Table 3. Fatty acid content of celery somatic embryos under normal culture conditions or reduced osmotic potential (for the last 2 days of the 10 culturing days), with or without $1 \mu \mathrm{M}$ ABA (applied on day 3 ).

\begin{tabular}{|c|c|c|c|c|c|c|c|c|}
\hline \multicolumn{2}{|c|}{ Treatment } & \multirow{2}{*}{\multicolumn{5}{|c|}{ Fatty acids (mg $\cdot \mathrm{g}^{-1}$ dry wt) }} & \multirow[b]{3}{*}{ Total } & \multirow{3}{*}{$\begin{array}{c}18: 1 \\
\text { to } \\
18: 2 \\
\text { ratio }\end{array}$} \\
\hline \multirow[b]{2}{*}{ Osmotica } & \multirow{2}{*}{$\begin{array}{l}\mathrm{ABA} \\
(\mu \mathrm{M})\end{array}$} & & & & & & & \\
\hline & & $16: 0$ & 18:0 & $18: 1$ & $18: 2$ & $18: 3$ & & \\
\hline \multirow{9}{*}{$\begin{array}{l}\text { Control } \\
\text { Sucrose } \\
\text { PEG }\end{array}$} & \multicolumn{8}{|c|}{ Main effect of osmoticum } \\
\hline & & $18.0 \mathrm{a}$ & 3.9 & $7.5 \mathrm{~b}$ & 51.5 & 1.7 & 82.7 & $0.15 \mathrm{~b}$ \\
\hline & & $16.4 \mathrm{ab}$ & 4.0 & $8.6 \mathrm{~b}$ & 46.8 & 1.7 & 77.4 & $0.17 \mathrm{ab}$ \\
\hline & & $15.6 \mathrm{~b}$ & 3.5 & $10.7 \mathrm{a}$ & 48.3 & 1.9 & 79.9 & $0.21 \mathrm{a}$ \\
\hline & & & NS & & NS & NS & NS & $*$ \\
\hline & \multicolumn{8}{|c|}{ Main effect of $A B A$} \\
\hline & 0 & 14.8 & 3.3 & 4.5 & 30.2 & 1.4 & 54.3 & 0.15 \\
\hline & 1 & 18.8 & 4.2 & 13.6 & 69.2 & 2.2 & 108.0 & 0.20 \\
\hline & & $* * *$ & $* *$ & $* * *$ & $* * *$ & $*$ & $* * *$ & $* *$ \\
\hline
\end{tabular}

${ }^{2}$ Lowercase letters indicate significant differences at $P=0.05$ according to Student-Newman-Keuls' multiple range test.

Nonsignificant or significant at $P=0.05,0.01$, or 0.001 , respectively.

Metabolite analyses. Samples of torpedo-shaped embryos from each treatment and replicate of Expt. 2 were analyzed for amino acids, carbohydrates, and fatty acids. Amino acids were extracted from 50 to $70 \mathrm{mg}$ of fresh embryos using the method described by Saranga et al. (1992). Fatty acids were extracted from $25 \mathrm{mg}$ of freeze-dried material using the method described by Kim and Janick (1990). Carbohydrates were analyzed using $30 \mathrm{mg}$ of freeze-dried material. Ethanol-soluble sugars were extracted by adding $7 \mathrm{ml}$ of $80 \%$ ethanol and heating to $80 \mathrm{C}$ for $30 \mathrm{~min}$. Ethanol was collected and the extraction was repeated two more times, after which extract was evaporated and volume adjusted to $8 \mathrm{ml}$. Aliquots of $0.5 \mathrm{ml}$ of the extracts were mixed with $0.5 \mathrm{ml}$ of $0.05 \mathrm{M}$ sodium acetate-acetic acid buffer, $\mathrm{pH} 4.5$, for determination of total reducing sugars, or the. same buffer with addition of $0.05 \%(\mathrm{w} / \mathrm{v})$ invertase was used for determination of total sugars and incubated $1 \mathrm{~h}$ at 37C. Samples were placed in a boiling water bath for $3 \mathrm{~min}, 2 \mathrm{ml}$ of dinitrosalicilic acid reagent (Miller, 1959) was added, and the samples returned to boiling water for $5 \mathrm{~min}$. Absorbance at $550 \mathrm{~nm}$ 
was measured spectrophotometrically and used to calculate reducing sugar based on glucose standards, or total sugars based on sucrose standards. Sucrose content was calculated as the difference between total and reducing sugars. Residue remaining after ethanol extraction was dried and used for starch determination. Samples were treated with amyloglucosidase, and glucose was determined by the glucose-oxidase system (MacRae, 1971). Absorbance at $540 \mathrm{~nm}$ was used to determine starch content based on glucose standards.

Data analysis. Analysis of variance was conducted using SAS software, general linear models procedure (Ray, 1982). Means were separated at $P=0.05$ by Student-Newman-Keuls' multiple range test.

\section{Results and Discussion}

Tolerance to partial desiccation. Imposition of high osmotic concentration in the EPM at the end of the embryo production cycle improved tolerance to partial desiccation (Table 1). The osmotic effect was consistent in Expts. 1 and 2, and in our preliminary experiments conducted with sucrose only (data not presented). In Expt. 1, all osmotica increased survival with similarly large effects achieved by PEG or sucrose and a smaller effect by trehalose (Table 1). In Expt. 2, osmoticum and ABA significantly interacted to affect embryo survival. Sucrose and PEG increased survival 2-fold in the absence of ABA, but with the high survival induced by ABA, there was no effect of osmotica. Conversion was also increased by either osmoticum. Sucrose treatment increased seedling fresh weight (10 days after rehydration) by $50 \%$ relative to the control and PEG treatment.

Improved tolerance to partial desiccation was achieved by either sucrose or PEG (Table 1). Thus, there is no evidence of a specific sucrose effect on desiccation tolerance; however, a specific effect on seedling vigor (increased fresh weight) was observed. It appears that increased tolerance to desiccation in somatic embryos induced by ABA, previously observed (Kitto and Janick, 1985; Senaratna et al., 1990) and confirmed here, overshadowed most of the osmotic effect. The small increase in survival induced by trehalose was less than the sucrose or PEG effects. There was no evidence for a desiccation protectant role of trehalose beyond its osmotic effect. Our results agree with those of Buchheim et al. (1989), who reported that high sucrose concentration induced maturation and desiccation tolerance in soybean [Glycine $\max$ (L.) Merr.] somatic embryos. Imposition of high osmotic concentration at the last 2 days of the embryo production cycle corresponds with the drop in water content as seeds mature (Quatrano, 1987). A step-wise, increased osmotic treatment would better mimic the development of zygotic seed and could further increase desiccation tolerance.

\section{Changes in metabolite concentration in somatic embryos}

Carbohydrates. Application of ABA induced a 10\% increase in embryo starch content (Table 2), in contrast to a 16-fold increase reported for alfalfa (Medicago sativa L.) somatic embryos (Fujii et al., 1989). Sucrose content of embryos also increased in response to ABA application, while reducing sugar content was unaffected.

High osmoticum (sucrose or PEG) induced a reduction in reducing sugars, and increased sucrose, but did not affect starch content of embryos (Table 2). Of these responses, only the change in embryo sucrose content was similar to that induced by ABA. Increasing medium sucrose concentration from $3 \%$ to $7 \%$ induced a proportional change in embryo sucrose content from 31 to $67 \mathrm{mg} \cdot \mathrm{g}^{-1}$ dry weight. PEG treatment resulted in embryo sucrose content similar to that of the sucrose treatment. These results indicate that sucrose may be the major osmolyte of celery embryos.

Fatty acids. Exogenous ABA applications increased the fatty acid content of somatic embryos and the ratio between oleic acid (18:1) to linoleic acid (18:2) (Table 3), as previously reported (Kim and Janick, 1990, 1991). Osmotic treatments did not affect total fatty acid content of the embryos. The PEG treatment induced a reduction in palmitic acid (16:0) and an increase in 18:1. The latter effect resulted in an increased 18:1 to $18: 2$ ratio, which was found to be associated with maturity and increased desiccation tolerance in celery somatic embryos (Kim and Janick, 1990, 1991).

Amino acids. ABA exposure reduced total amino acid concentration but substantially increased proline and $\gamma$-aminobutyrate (GABA) in somatic embryos (Table 4), as observed previously (Saranga et al., 1992). Imposition of higher osmotic

Table 4. Amino acid content of celery somatic embryos under normal culture conditions or reduced osmotic potential on the last 2 days of the 10 culturing days, with or without ABA (applied on day 3).

\begin{tabular}{|c|c|c|c|c|c|c|c|c|c|c|c|c|c|}
\hline \multicolumn{2}{|c|}{ Treatment } & \multicolumn{12}{|c|}{ Amino acids $\left(\mu \mathrm{mol} \cdot \mathrm{g}^{-1}\right.$ fresh $\left.\mathrm{wt}\right)$} \\
\hline Osmoticum & $\begin{array}{l}\text { ABA } \\
(\mu \mathrm{M})\end{array}$ & Ala & GABA & $\begin{array}{c}\text { Asp }+ \\
\text { Asn }\end{array}$ & $\begin{array}{c}\mathrm{Glu}+ \\
\text { Gln }\end{array}$ & Gly & His & Leu & Pro & Ser & Thre & Val & Total \\
\hline \multirow[t]{2}{*}{ Control } & 0 & 28.3 & 4.0 & 6.6 & 104.8 & 0.7 & 1.8 & 1.4 & 3.3 & 4.2 & 2.0 & 5.5 & 166 \\
\hline & 1 & 30.0 & 5.2 & 8.6 & 78.2 & 0.7 & 1.8 & 1.3 & 6.9 & 3.9 & 1.9 & 4.5 & 137 \\
\hline \multirow[t]{2}{*}{ Sucrose } & 0 & 39.4 & 6.2 & 7.5 & 111.0 & 0.9 & 2.0 & 1.5 & 14.8 & 5.8 & 2.5 & 6.7 & 201 \\
\hline & 1 & 23.4 & 8.6 & 12.9 & 99.6 & 0.9 & 2.6 & 1.5 & 29.3 & 6.9 & 2.9 & 5.0 & 199 \\
\hline \multirow[t]{3}{*}{ PEG } & 0 & 25.1 & 5.6 & 9.3 & 130.7 & 0.8 & 3.0 & 1.7 & 13.5 & 5.8 & 2.8 & 6.3 & 208 \\
\hline & 1 & 22.2 & 7.2 & 13.4 & 117.6 & 1.0 & 2.4 & 1.8 & 28.4 & 6.4 & 3.4 & 6.5 & 215 \\
\hline & & \multicolumn{12}{|c|}{ Main effect of osmoticum } \\
\hline Control & & $29.1 \mathrm{a}^{\mathrm{z}}$ & $4.6 \mathrm{~b}$ & $7.6 \mathrm{~b}$ & $91.6 \mathrm{~b}$ & $0.7 \mathrm{~b}$ & $1.8 \mathrm{~b}$ & $1.4 \mathrm{~b}$ & $5.1 \mathrm{~b}$ & $4.1 \mathrm{~b}$ & $2.0 \mathrm{c}$ & $5.0 \mathrm{~b}$ & $151 \mathrm{~b}$ \\
\hline Sucrose & & $31.4 \mathrm{a}$ & $7.4 \mathrm{a}$ & $10.2 \mathrm{a}$ & $105.3 \mathrm{~b}$ & $0.9 \mathrm{a}$ & $2.3 \mathrm{a}$ & $1.5 \mathrm{~b}$ & $22.0 \mathrm{a}$ & $6.4 \mathrm{a}$ & $2.7 \mathrm{~b}$ & $5.9 \mathrm{ab}$ & $200 \mathrm{ab}$ \\
\hline \multirow[t]{5}{*}{ PEG } & & $\underset{* * *}{23.5 \mathrm{~b}}$ & $\begin{array}{c}6.5 \mathrm{a} \\
* * *\end{array}$ & $\begin{array}{c}11.6 \mathrm{a} \\
* *\end{array}$ & $\begin{array}{c}123.2 \mathrm{a} \\
* *\end{array}$ & $\underset{* *}{0.9 \mathrm{a}}$ & $\begin{array}{c}2.6 \mathrm{a} \\
*\end{array}$ & ${ }_{* *}^{1.8 \mathrm{a}}$ & $\begin{array}{c}22.1 \mathrm{a} \\
* * *\end{array}$ & $\underset{* * *}{6.2 \mathrm{a}}$ & $\begin{array}{c}3.1 \mathrm{a} \\
* * *\end{array}$ & $\begin{array}{c}6.4 \mathrm{a} \\
*\end{array}$ & $\begin{array}{c}212 \mathrm{a} \\
* * *\end{array}$ \\
\hline & & \multicolumn{12}{|c|}{ Main effect of $A B A$} \\
\hline & 0 & 31.5 & 5.2 & 7.7 & 114.2 & 0.8 & 2.2 & 1.5 & 10.3 & 5.2 & 2.4 & 6.2 & 190 \\
\hline & 1 & 21.9 & 7.0 & 11.6 & 98.5 & 0.9 & 2.3 & 1.5 & 21.6 & 5.8 & 2.7 & 5.2 & 184 \\
\hline & & $* * *$ & $* * *$ & $* *$ & $*$ & NS & NS & NS & $* * *$ & NS & $*$ & $*$ & $\begin{array}{r}104 \\
\text { NS }\end{array}$ \\
\hline
\end{tabular}

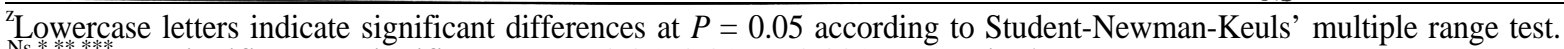
Nonsignificant or significant at $P=0.05,0.01$, or 0.001 , respectively. 
concentration, by exposure to either sucrose or PEG, similarly affected most amino acids and increased total amino acid content by $30 \%$ to $40 \%$. This change could be, at least partly, due to reduction in water content (data not available). In contrast, the addition of ABA slightly reduced total (not significant) amino acids. The increases in most individual amino acids under the osmotic treatments generally were in concordance with the changes induced by ABA. However, glutamine plus glutamate content was greatly increased by osmotic concentrations but was reduced by ABA; this deviation accounts for most of the difference between the effects of osmoticurn and ABA on total amino acid content. The most striking effect of the high osmotic treatments was the 4-fold increase in proline. A similar trend was found in tobacco (Nicotiana tabacum L.) cells exposed to $\mathrm{NaCl}$ stress with or without ABA (LaRosa et al., 1987).

\section{Metabolites and tolerance to partial desiccation}

In a previous paper (Saranga et al., 1992), we concluded that proline has an important role in conferring to partial desiccation tolerance to somatic embryos. In the present study, a proline content of $6.9 \mu \mathrm{mol} \cdot \mathrm{g}^{-1}$ fresh weight, induced by ABA in the control, was associated with $93.3 \%$ survival and $60.0 \%$ conversion (Tables 1 and 4). In the same experiment, proline at $14.8 \mu \mathrm{mol} \cdot \mathrm{g}^{-1}$ fresh weight, induced by high osmoticum without ABA (mean of sucrose and PEG), was associated with $63.4 \%$ survival and $25.5 \%$ conversion. This difference suggests that proline is not the only factor by which $\mathrm{ABA}$ confers tolerance to partial desiccation. The effects of ABA on metabolites differed from those of osmoticum in the increased starch, decreased glutamine + glutamate, and largely increased fatty acid contents (Tables 2-4). Changes in the proportions of fatty acids, previously reported to be associated with desiccation tolerance (Kim and Janick, 1990, 1991), may be one of the additional factors contributing to the tolerance induced by ABA. It would be of interest to know if other factors reported to increase desiccation tolerance, such as chilling, inoculum density (Kitto and Janick, 1985), and heat shock (Senaratna et al., 1989), also influence proline and fatty acid levels.

\section{Literature Cited}

Ammirato, P.V. 1983. The regulation of somatic embryo development in plant cell cultures: Suspension culture techniques and hormone requirements. Biotechnology 1:68-74.

Buchheim, J.A., S.M. Colburn, and J.P. Ranch. 1989. Maturation of soybean somatic embryos and the transition to plantlet growth. Plant Physiol. 89:768-775.
Crowe, J.H., L.M. Crowe, and D. Chapman. 1984. Preservation of membranes in anhydrobiotic organisms: The role of trehalose. Science 223:701-703.

Finkelstein, R.R. and M.L. Crouch. 1986. Rapeseed embryo development in culture on high osmoticum is similar to that in seeds. Plant Physiol. 81:907-912.

Fujii, J.A., D. Slade, R. Olsen, S.E. Ruzin, and K. Redenbaugh. 1989. ABA maturation and starch accumulation in alfalfa somatic embryos. In Vitro Cell Dev. Biol. 25:61A(Abstr.)

Janick, J., S.L. Kitto, and Y.-H. Kim. 1989. Production of synthetic seed by desiccation and encapsulation. In Vitro Cell. Dev. Biol. 25:1167-1172.

Kim, Y.-H. and J. Janick. 1989. ABA and Polyox-encapsulation or high humidity increases survival of desiccated somatic embryos of celery. HortScience 24:674-676.

Kim, Y.-H. and J. Janick. 1990. Synthetic seed technology: Improving desiccation tolerance of somatic embryos of celery. Acta Hort. 280:2328.

Kim, Y.-H. and J. Janick. 1991. Abscisic acid and proline improves desiccation tolerance and increases fatty acid content of celery somatic embryos. Plant Cell, Tissue Organ Cult. 24:83-89.

Kitto, S.L. and J. Janick. 1985. Production of synthetic seeds by encapsulating asexual embryos of carrot. J. Amer. Soc. Hort. Sci. 110:277-282.

LaRosa, P.C., P.M. Hasegawa, D. Rhodes, J.M. Clithero, A-E.A. Watad, and R.A. Bressan. 1987. Abscisic acid stimulated osmotic adjustment and its involvement in adaptation of tobacco cells to NaCl. Plant Physiol. 85:174-181.

MacRae, J.C. 1971. Quantitative measurement of starch in very small amounts of leaf tissue. Planta 96:101-108.

Miller, G.L. 1959. Use of dinitrosalicylic acid reagent for determination of reducing sugar. Anal. Chem. 31:426-428.

Murashige, T. and F. Skoog. 1962. A revised medium for rapid growth and bioassays with tobacco tissue cultures. Physiol. Plant. 15:473497.

Quatrano, R.S. 1987. The role of hormones during seed development, p. 494-514. In: P.J. Davies (ed.). Plant hormones and their role in plant growth and development. Martinus Nijhoff, Dordecht.

Ray, A.A. (ed.). 1982. SAS user's guide: Statistics. SAS Institute, Cary, N.C. p. 584.

Saranga, Y., D. Rhodes, and J. Janick. 1992. Changes in amino acid composition associated with tolerance to partial desiccation of celery somatic embryos. J. Amer. Soc. Hort. Sci. 117:337-341.

Senaratna, T., B.D. McKersie, and S.R. Bowley. 1989. Desiccation tolerance of alfalfa (Medicago sativa L.) somatic embryos. Influence of ABA, stress pretreatments, and drying rates. Plant Sci. 65:253259.

Senaratna, T., B.D. McKersie, and S.R. Bowley. 1990. Artificial seeds of alfalfa (Medicago sativa L.). Induction of desiccation tolerance in somatic embryos. In Vitro Cell Dev. Biol. 26:85-90. 